\title{
A REEDUCAÇÃO POSTURAL GLOBAL É UMA FERRAMENTA ÚTIL NO TRATAMENTO DA INCONTINÊNCIA URINÁRIA DE ESFORÇO FEMININA?
}

A incontinência urinária de esforço é uma condição relativamente freqüente. A evidência resultante de diversos estudos anteriormente publicados implica consistentemente a disfunção dos músculos do assoalho pélvico na incontinência urinária de esforço. Desde a publicação das normas de orientação clínica para o tratamento da incontinência urinária, em 1992, pelo US Department of Health and Human Services, o tratamento conservador da incontinência urinária de esforço é promovido como medida terapêutica de primeira linha pela sua eficácia, baixo risco e baixo custo'. Nesse sentido, o treino muscular do assoalho pélvico tem sido a estratégia de eleição no tratamento conservador de mulheres com incontinência urinária de esforço. Uma recente revisão sistemática, que incluiu seis estudos e dados de 403 mulheres, indicou que o treino muscular do assoalho pélvico é mais eficaz no tratamento da incontinência urinária de esforço que a não realização de qualquer tratamento ou tratamento placebo².

Uma nova linha de investigação foi aberta por Fozzatti et al., no atual volume da Revista da Associação Médica Brasileira, ao avaliar os efeitos da reeducação postural global nos sintomas da incontinência urinária de esforço e na qualidade de vida em mulheres incontinentes. Os autores demonstraram que o tratamento conservador da incontinência urinária de esforço através da reeducação postural global melhora os sintomas e a qualidade de vida sugerindo que, tal como noutras patologias ${ }^{3}$, também na incontinência urinária de esforço a reeducação postural global pode-se constituir como uma terapia válida e promissora.

O estudo de Fozzatti et al. aponta outra direção na qual a ciência nesta área específica do conhecimento está a viajar. As alterações posturais causadas por modificação estrutural são uma das causas da diminuição da capacidade funcional do assoalho pélvico e, conseqüentemente, da incontinência urinária de esforço. Desta forma, a reeducação postural global, ao procurar intervir na causa, poderá ter efeitos benéficos na conseqüência. Esta premissa poderá ser um bom ponto de partida para a investigação neste domínio de conhecimento, no entanto os resultados de Fozzatti et al. não a suportam totalmente. A avaliação postural inicial indicou a existência de alterações posturais condizentes com o comprometimento da função do assoalho pélvico, contudo não são apresentados dados da avaliação postural após a intervenção. Dados que poderiam ajudar a compreender a evolução da sintomatologia e da qualidade de vida e que poderiam consubstanciar a utilidade da reeducação postural global, por, eventualmente, se correlacionarem com os efeitos benéficos observados.

Um estudo de três casos de incontinência urinária de esforço feminina indicou que a correção postural do complexo lombopélvico-femoral associado ao fortalecimento do assoalho pélvico induz diminuição da perda urinária, ganho de força muscular do assoalho pélvico e diminuição das sensações de umidade e desconforto ${ }^{4}$. Neste sentido será útil que futuros estudos comparem a reeducação postural global a outras opções terapêuticas; e, que por outro lado, também, avaliem o seu efeito aditivo a outras modalidades terapêuticas.

Da leitura dos resultados destaca-se a existência de 12\% da amostra que não apresentou melhoria subjetiva da incontinência urinária de esforço. As diferenças interindividuais de resposta à intervenção em função do grande intervalo de idade da população em estudo e da grande amplitude nos anos de queixas de incontinência poderão ter condicionado estes resultados. Desta forma, emerge a necessidade de em futuros estudos se utilizar intervalos etários mais curtos, procurando desta forma esclarecer se o tratamento por reeducação postural global segue o mesmo padrão do treino muscular do assoalho pélvico, cujo efeito do tratamento é maior em jovens adultas comparativamente a mulheres pós-menopausa ${ }^{2,5-6}$. Importa também estudar se os resultados da intervenção são condicionados pelo nível inicial de alterações posturais e de disfunção do assoalho pélvico, procurando estabelecer um limiar de disfunção a partir do qual a resposta à reeducação postural global deixa de ser favorável.

A reeducação postural global é uma ferramenta útil no tratamento da incontinência urinária de esforço feminina? Parece que a resposta a esta questão é afirmativa, contudo futuros estudos randomizados, controlados, são necessários para afirmar de forma clara que a reeducação postural global é uma alternativa e/ou um coadjuvante válido no tratamento da incontinência urinária de esforço. E, paralelamente, explicar o exato mecanismo pelo qual a reeducação postural global melhora a incontinência.

\section{Faculdade de Desporto da Universidade do Porto, Portugal FISIOFERNANDO@GMAIL.COM}

\section{Referências}

I.Fantl JA, Newman DK, Colling J, DeLancey JO, Keeys C, Loughery R, et al. Urinary incontinence in adults: acute and chronic management: clinical practice guideline, N. 2; 1996 Update. Rockville: US Department of Health and Human Services, Public Health Service, Agency for Health Care Policy and Research; 1996. AHCPR Publication N. 96-0682.

2. Hay-Smith EJ, Dumoulin C. Pelvic floor muscle training versus no treatment, or inactive control treatments, for urinary incontinence in women. Cochrane Database Syst Rev. 2006;( ( ):CD005654

3. Ribeiro $F$, Leite $M$, Silva F, Sousa O. Exercício físico no tratamento da espondilite anquilosante: uma revisão sistemática. Acta Reumatol Port. 2007;32:129-37.

4.Rodrigues NC, Scherma D, Mesquita RA, Oliveira J. Exercícios perineais, electroestimulação e correção postural na incontinência urinária - estudo de casos. Fisioter Mov. 2005; I 8(3):23-29.

5. Hay-Smith EJ, Bo K, Berghmans LC, Hendriks HJ, Bie RA, Van Waalwijk van Doorn ES. Pelvic floor muscle training for urinary incontinence in women. Cochrane Database Syst Rev. 2006;(I):CD00 I 407.

6. Choi H, Palmer MH, Park J. Meta-analysis of pelvic floor muscle training: randomized controlled trials in incontinent women. Nurs Res. 2007;56(4):226-34.

7.Fozzatti MCM, Palma P, Herrmann V, Dambros M. Impacto da reeducação postural global no tratamento da incontinência urinária de esforço feminina. Rev Assoc Med Bras. 2008; 54(1): 17-22. 